\title{
Car Selection Using Hybrid Fuzzy AHP and Grey Relation Analysis Approach
}

\author{
Amol Nayakappa Patil*, Niraj G. Pai Bhale, Nagaraj Raikar, M. Prabhakaran \\ Department of Mechanical Engineering, Agnel Institute of Technology and Design, Assagao, Bardez-Goa, India
}

\begin{abstract}
Opting right alternative between numerous alternatives is really complicated decision, which becomes more complex when alternatives are conflicting in nature and there is minor difference among alternatives. Complexity in decision making can be minimized if analytical methods are used for selection of alternatives. In everyday life, we often have to make decisions and several times we come across circumstances where the decision to make is selection of best alternative among various alternatives. This paper demonstrates application of Fuzzy Analytical Hierarchical Process approach integrated with Grey Relation Analysis to select the best car among various cars available in the market taking into consideration all the required qualitative and quantitative decision aspects.
\end{abstract}

Keywords: Fuzzy Analytical Hierarchical Process (AHP); Grey Relation Analysis (GRA); Multi Criteria Decision Making; Conflicting Alternatives; Fuzzy Triangular Number; Priority Weights; Pairwise Comparison; Complex Decision

(Submitted on May 8, 2017; Revised on June 28, 2017; Accepted on August 13, 2017)

(C) 2017 Totem Publisher, Inc. All rights reserved.

\section{Introduction}

Human success depends upon right decisions made at the right time. In today's life, humans come across different decision making situations and failure to make the right decision at the right time may possibly lead to losses which are either tangible or intangible in nature. Making a decision hastily or delaying a decision is not acceptable in real life. Hasty decision may result in selection of wrong opportunity and slow decision making may result in missing an excellent opportunity. Decision making becomes more complex if there are numerous opportunities or alternatives which are subjective in nature [1]. In complex situations with multi criteria, decision making becomes a difficult task and hence requires a systematic and comprehensive analytical approach to convert numerous subjective alternatives into quantitative information to aid in decision making. This paper demonstrates application of analytical approach for day today life decision making such as car selection.

Due to globalization, short time to launch a product, and ever changing customer requirements, car manufactures continuously upgrade their products to delight customers. Introduction of new models by car manufacturers or alteration of existing models with additional features, supported by discount offers by dealers, loan offers given by banks and increasing fuel prices, put pressure on the customer while making decision of purchasing a new car. Car selection by customers in India is based on important qualitative criteria's which includes cars external appearance, car interiors, add on features, on road reliability, after sales service, and important quantitative criteria like price, mileage, displacement, power, torque and service location. Comparing available models within required budget considering important qualitative and quantitative criteria and deciding best car among all available cars is a complex decision. To select the best car among all available cars requires a good analytical approach that considers both qualitative and quantitative criteria's.

Many methods are introduced by researchers to compare alternatives and select the best alternative among all available alternatives. Of all, Analytical Hierarchy Process approach is widely used [13]. Fuzzy AHP is an improvement over AHP, which takes into account vagueness and imprecision in human decisions while comparing qualitative features of numerous alternatives [7]. Grey Relation Analysis (GRA) can be used to compare quantitative features with numerous alternatives [12]. 
Application of Fuzzy AHP and GRA was demonstrated for selection of desalination system with five desalination alternatives and with five different criteria's [4]. Site selection for manufacturing plant is dynamic problem with multi criteria decision environment and group of qualitative and quantitative criteria, AHP and GRA combined approach was used to solve site selection problem [6]. Mathematical model, integration of Fuzzy AHP and GRA was used to select competent agent constructive enterprise for public projects. Evaluation of Agent constructive enterprise was done based on bidding evaluation indexes [5].

\section{Proposed Integrated Fuzzy AHP and GRA model for Car Selection}

The proposed framework for the car selection is described in figure 1. Framework uses Fuzzy AHP and GRA integrated approach. Fuzzy AHP is a combination of AHP and Fuzzy theory. Fuzzy AHP uses linguistic scale, which converts expert's opinion into Fuzzy number and membership function in pairwise comparison matrix. Thus expert's opinion in Fuzzy AHP approaches human thinking model and more reasonable evaluation [14]. Fuzzy AHP can be applied to many real life fuzziness concepts. Systems that lack information is termed as Grey System. Grey system defines a situation with needed information that is not exactly available as black and needed information that is exactly available as white. Grey system establishes a relation between black and white. It is system with part of the information known and part of the information unknown. GRA is one of the components of Grey theory, used for comparing quantitative data in multi attribute cases [2].

In proposed framework, car selection decision is designed in a hierarchy way with uppermost level as car selection decision. Car selection problem is followed by identifying qualitative and quantitative criteria's with open ended discussion by family members. Qualitative criteria identified includes car external appearance, car interiors, add on features like GPS, fog lamps, rear wiper and defoggers, OVRM, rear view camera, bottle holder, power windows, music system etc, on road reliability and after sales service as sub criteria's under qualitative criterion. The car price, mileage, displacement, power, torque and service location are considered as sub-criteria under quantitative criterion.

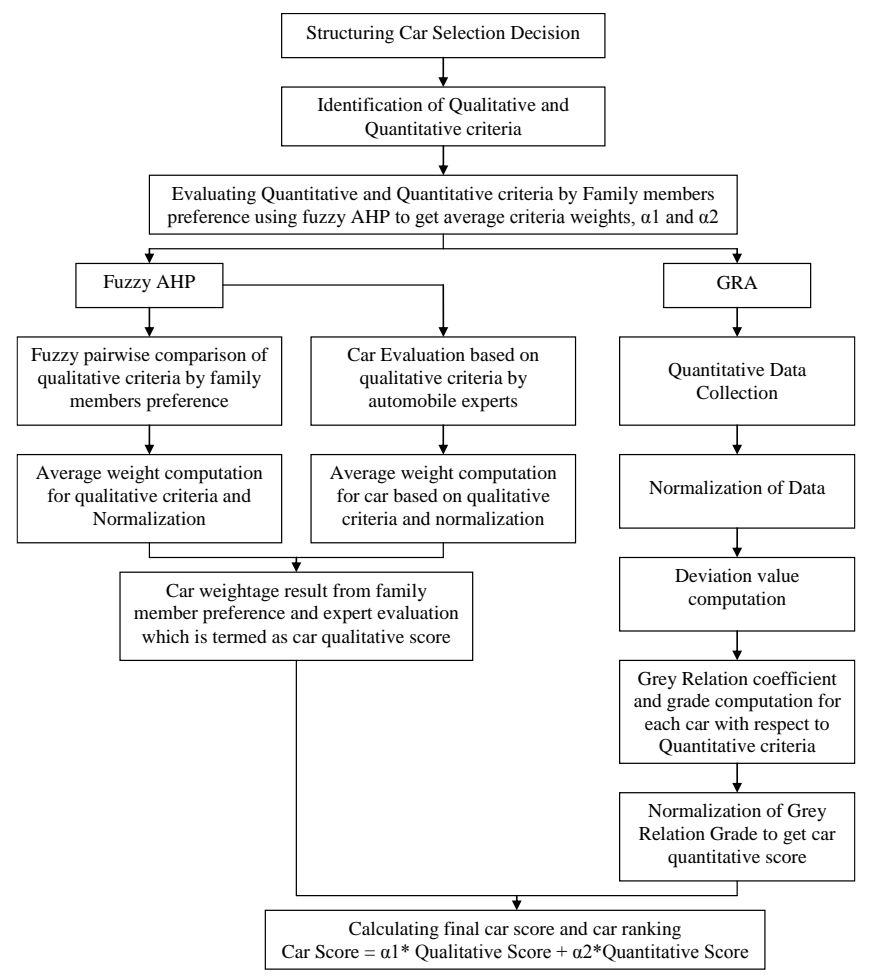

Fig. 1 Car Selection proposed methodology framework

Initially Fuzzy AHP is used to find importance of qualitative and quantitative criteria according to customer judgment. Further customer's family opinion is reviewed to find importance of sub criteria under qualitative and quantitative criteria using Fuzzy AHP. Automobile Experts opinion is later obtained to compare various short listed car models in given budget using Fuzzy AHP approach for qualitative criteria. Grey Relation Analysis is used to assign weights to the quantitative criteria. Finally weights of qualitative and quantitative sub criteria are combined to decide rank of cars among short listed car models. 


\subsection{Fuzzy AHP (Chang's Extent Analysis) for Qualitative Features}

The fuzzy AHP methodology is an extension of Saaty's AHP which uses fuzzy set theory. Fuzzy AHP is a good approach for multiple criteria decision making in fuzzy, unclear, and vague environments [15]. Fuzzy AHP uses ratio scale to define strength of the alternatives corresponding to qualitative features. Therefore, fuzzy judgment matrix can be constructed based on opinion and converted to final weight of alternative using Chang's Extent Analysis to represent single fuzzy number. Method uses Chang's extent analysis as it is relatively easier approach to fuzzy case and gives unique solution. Chang's extent analysis on fuzzy AHP depends on the degree of possibilities of each criterion [8,11]. Methodology uses fuzzy triangular numbers with linguistic expression as shown in Table 1 [11]. Triangular fuzzy numbers are easy to use and calculate. Also, modeling using triangular number is effective where decision problem information is subjective and imprecise.

Table 1. Fuzzy AHP Scale

\begin{tabular}{|l|l|l|l|}
\hline Linguistic Scale & Fuzzy Number & Triangular Fuzzy Number & Linguistic Scale \\
\hline Just Equal & EI & $(1,1,1)$ & Same \\
\hline Weakly Important & WI & $(1,3,5)$ & Slightly Better \\
\hline Strong Important & SI & $(3,5,7)$ & Moderate Better \\
\hline Very Strong Important & VI & $(7,7,9)$ & Much Better \\
\hline Immense Important & II & Best \\
\hline
\end{tabular}

Customers and their families have been asked to give their priority pair-wise comparisons of qualitative features in the form of linguistic expression to get weights and experts have been asked to compare car models based on linguistic expression for qualitative features. Chang's extent analysis gives final weight to the qualitative features and also final weights to car models. Weights of criteria and weights of car features is combined together to get final weight for each car model based on qualitative criteria.

\subsection{Grey Relation Analysis for quantitative features}

Quantitative criteria such as price, mileage, displacement, power, torque, and service location have tremendous impact on a decision. Methodology uses GRA proposed by Julong Deng in 1982. It has been used in many areas since that time. GRA has been used in measuring financial performance, logistic performance and also for optimization of process. GRA has also been used in integration with other methods for supplier selection problems [9]. Grey theory is used to solve problems that are complex in nature and having incomplete information. The system with known information is termed as white, system with unknown information is termed as black, and system in between is termed as grey. The grey approach normalizes data with larger the better or smaller the better responses [10]. Deviation, grey relation coefficient and grade are calculated to get final score.

\subsection{Fuzzy AHP and GRA integration}

Qualitative and Quantitative weights are than combined together to obtain final weight of cars and final rank. Final score of car is given by following expression from [11]:

$$
\text { Car Score }=\alpha 1 * \text { Qualitative Score }+\alpha 2 * \text { Quantitative Score }
$$

where, $\alpha 1$ and $\alpha 2$ are weights of qualitative and quantitative criteria decided by car customer, i.e. importance given by customer towards car features.

\section{Constructing Car selection model}

Car customer X from Goa, India has been considered to check validity of proposed model. X is from remote area of Goa and a lone earning member from his family, with a monthly income of Rupees $35 \mathrm{~K}$ and is planning to buy a new first car for family of five members. Average running of car will be around $15 \mathrm{kms}$ daily; hence, he has decided to purchase a petrol car within 5.5 lakhs budget. Based on requirements, budget and discussion with family members, five cars have been shortlisted. Car 1 is a popular brand, with good sales and service preference, but has a box type of design. Car 2 is also a well-known brand but has less service stations, so getting the car serviced might be inconvenient. Car 3 is a Japanese brand that has been recently launched in India and is marketed by another partner. Car 4 is also a newly launched car and Car 5 is an Indian branded car. Car 3, Car 4, and Car 5 have only two service centers in the entire Goa. Selecting the best car out of five alternatives is a difficult and complex decision for the customer. So, integrated fuzzy AHP and GRA model is used to select the best car. Car selection can be evaluated by external appearance, car interior appearance, add on features, on road reliability, 
after sales service as qualitative criteria and price, mileage, displacement power, torque, service location as quantitative criteria.

\subsection{Fuzzy AHP Model}

Figure 2, represents the AHP hierarchy for the car selection problem for all qualitative criteria. The hierarchy represents the various levels of the problem in terms of the overall goal, criteria, sub criteria and the decision alternative. Once the hierarchy is constructed for the car selection decision, perform pair-wise comparison of elements in one level relative to a single element in a level immediately above it to derive local priorities of these elements that reflect their relative contribution to the subject of comparison [3].

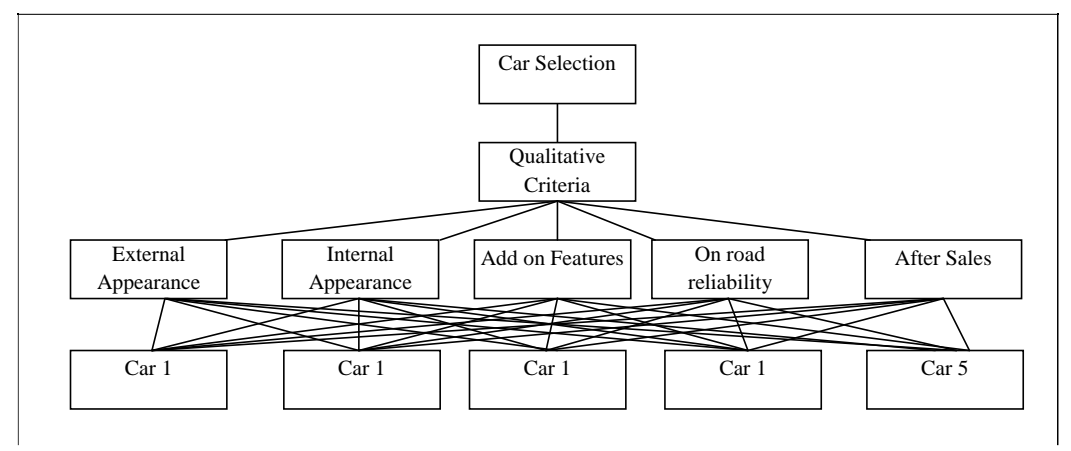

Fig. 2 Hierarchy Structure for Decision Goal

To finalize qualitative criteria weights, opinions of five family members have been considered using linguistic expressions. Here, opinions of all five members are considered equally important. Also, judgments of five automobile experts have been taken to carry out pair- wise comparison of shortlisted car models in respect to qualitative criteria's.

Table 2 shows a sample pair-wise comparison of qualitative and quantitative criteria done by family member 1 . The same work out was carried out by all five family members and the average of all was noted in Table 3 , which was further normalized to get the importance of qualitative and quantitative criteria's. Later family members are asked to compare criteria's as shown in Table 4 and average of all is taken in Table 5. Five auto experts evaluates all car models against all qualitative criteria's. Depicted in Table 6 is external appearance, Table 8 is car interiors, Table 10 is add-on features, Table 12 is road reliability and Table 14 is after sales. Average weightage for all car models is calculated and noted in Table 7, Table 9, Table 11, Table 13 and Table 15. Aggregate car weightage for short listed car models considering importance of qualitative criteria's is calculated and summarized in Table 16.

Table 2. Evaluating Qualitative and Quantitative criteria- Member 1

\begin{tabular}{|c|c|c|c|}
\hline & Quantitative & Qualitative & SI \\
\hline Quantitative & EI & Weightage & $(0.42,0.83,1.56)$ \\
\hline Qualitative & & $(0.12,0.17,0.26)$ \\
\hline
\end{tabular}

\begin{tabular}{|c|c|c|c|}
\hline Table 3. Average weightage between Qualitative and Quantitative Criteria \\
\hline Criteria & Average Weightage & Defuzzification & Normalization \\
\hline Quantitative & $(0.47,0.98,1.49)$ & 0.98 & 0.65 \\
\hline Qualitative & $(0.11,0.58,0.89)$ & 0.53 & 0.35 \\
\hline
\end{tabular}

\begin{tabular}{|c|c|c|c|c|c|c|}
\hline Criteria & $\begin{array}{c}\text { External } \\
\text { Appearance }\end{array}$ & Car Interiors & Add on Features & $\begin{array}{c}\text { On Road } \\
\text { Reliability }\end{array}$ & $\begin{array}{l}\text { After Sales } \\
\text { Service }\end{array}$ & Weightage \\
\hline $\begin{array}{c}\text { External } \\
\text { Appearance }\end{array}$ & EI & WI & VI & SI & II & $(0.20,0.39,0.73)$ \\
\hline Car Interiors & & EI & SI & WI & VI & $(0.12,0.26,054)$ \\
\hline Add on Features & & & EI & SI & VI & $(0.11,0.21,0.41)$ \\
\hline $\begin{array}{l}\text { On Road } \\
\text { Reliability }\end{array}$ & & & & EI & SI & $(0.05,0.10,0.22)$ \\
\hline $\begin{array}{c}\text { After Sales } \\
\text { Service }\end{array}$ & & & & & EI & $(0.02,0.03,0.04)$ \\
\hline
\end{tabular}


Table 5. Average weightage between Qualitative Criteria

\begin{tabular}{|c|c|c|c|}
\hline Criteria & Average Weightage & Defuzzification & Normalization \\
\hline External Appearance & $(0.35,0.75,1.63)$ & 0.91 & 0.36 \\
\hline Car Interiors & $(0.20,0.46,1.10)$ & 0.59 & 0.23 \\
\hline Add on Features & $0.15,0.32,0.74)$ & 0.40 & 0.22 \\
0.09 & 0.40 \\
\hline On Road Reliability & $(0.09,0.17,0.39)$ & 0.16 & \\
\hline After Sales Service & $(0.09,0.31,0.79)$ & 0.4 & 0.16 \\
\hline
\end{tabular}

Table 6. Cars Evaluation for External Appearance- Expert 1

\begin{tabular}{|c|c|c|c|c|c|c|}
\hline Cars & Car 1 & Car 2 & Car 3 & Car 4 & Car 5 & Weightage \\
\hline Car 1 & $(1,1,1)$ & $(1 / 5,1 / 3,1)$ & $(3,5,7)$ & $(1,3,5)$ & $(1 / 7,1 / 5,1 / 3)$ & $(0.07,0.16,0.35)$ \\
\hline Car 2 & & $(1,1,1)$ & $(5,7,9)$ & $(3,5,7)$ & $(1 / 9,1 / 7,1 / 5)$ & $(0.12,0.26,0.55)$ \\
\hline Car 3 & & & $(1,1,1)$ & $(1 / 5,1 / 3,1)$ & $(1 / 9,1 / 9,1 / 7)$ & $(0.02,0.03,0.07)$ \\
\hline Car 4 & & & & $(1,1,1)$ & $(1 / 9,1 / 7,1 / 5)$ & $(0.03,0.08,0.19)$ \\
\hline Car 5 & & & & & $(1,1,1)$ & $(0.26,0.47,0.86)$ \\
\hline
\end{tabular}

Table 7. Average Weightage of cars for external appearance

\begin{tabular}{|c|c|c|c|}
\hline Cars & Average Weightage & Defuzzification & Normalization \\
\hline Car 1 & $(0.13,0.31,0.67)$ & 0.37 & 0.16 \\
\hline Car 2 & $(0.14,0.29,0.61)$ & 0.35 & 0.15 \\
\hline Car 3 & $(0.20,0.34,0.65)$ & 0.40 & 0.17 \\
\hline Car 4 & $(0.06,0.16,0.37)$ & 0.19 & \\
\hline Car 5 & $(0.50,0.90,1.59)$ & 1 & 0.08 \\
\hline
\end{tabular}

Table 8. Cars Evaluation for Car Interiors- Expert 1

\begin{tabular}{|c|c|c|c|c|c|c|}
\hline Cars & Car 1 & Car 2 & Car 3 & Car 4 & Car 5 & Weightage \\
\hline Car 1 & $(1,1,1)$ & $(1,3,5)$ & $(3,5,7)$ & $(7,9,9)$ & $(5,7,9)$ & $(0.22,0.44,0.85)$ \\
\hline Car 2 & & $(1,1,1)$ & $(1,3,5)$ & $(5,7,9)$ & $(3,5,7)$ & $(0.13,0.28,0.63)$ \\
\hline Car 3 & & & $(1,1,1)$ & $(3,5,7)$ & $(1,3,5)$ & $(0.07,0.17,0.39)$ \\
\hline Car 4 & & & & $(1,1,1)$ & $(1,3,5)$ & $(0.03,0.08,0.18)$ \\
\hline Car 5 & & & & & $(1,1,1)$ & $(0.02,0.04,0.10)$ \\
\hline
\end{tabular}

Table 9. Average Weightage of cars for Interiors

\begin{tabular}{|c|c|c|c|}
\hline \multicolumn{5}{|c|}{ Table 9. Average Weightage of cars for Interiors } \\
\hline Cars & Average Weightage & Defuzzification & Normalization \\
\hline Car 1 & $(0.25,0.53,1.09)$ & 0.62 & 0.25 \\
\hline Car 2 & $(0.28,0.62,1.36)$ & 0.76 & 0.31 \\
\hline Car 3 & $(0.09,0.20,0.48)$ & 0.26 & 0.11 \\
\hline Car 4 & $(0.11,0.27,0.66)$ & 0.35 & 0.14 \\
\hline Car 5 & $(0.18,0.37,0.83)$ & 0.46 & 0.19 \\
\hline
\end{tabular}

Table 10. Cars Evaluation for Add-on Features- Expert 1

\begin{tabular}{|c|c|c|c|c|c|c|}
\hline Cars & Car 1 & Car 2 & Car 3 & Car 4 & Car 5 & Weightage \\
\hline Car 1 & $(1,1,1)$ & $(1,3,5)$ & $(5,7,9)$ & $(3,5,7)$ & $(7,9,9)$ & $(0.22,0.44,0.85)$ \\
\hline Car 2 & & $(1,1,1)$ & $(3,5,7)$ & $(1,3,5)$ & $(5,7,9)$ & $(0.13,0.28,0.63)$ \\
\hline Car 3 & & & $(1,1,1)$ & $(1 / 5,1 / 3,1)$ & $(1,3,5)$ & $(0.03,0.08,0.21)$ \\
\hline Car 4 & & & & $(1,1,1)$ & $(3,5,7)$ & $(0.07,0.17,0.39)$ \\
\hline Car 5 & & & & & $(1,1,1)$ & $(0.02,0.03,0.07)$ \\
\hline
\end{tabular}

Table 11. Average Weightage of cars for Add on Features

\begin{tabular}{|c|c|c|c|}
\hline Cars & Average Weightage & Defuzzification & Normalization \\
\hline Car 1 & $(0.43,0.87,1.70)$ & 1.0 & 0.42 \\
\hline Car 2 & $(0.26,0.51,1.26)$ & 0.7 & 0.15 \\
\hline Car 3 & $(0.05,0.11,0.28)$ & 0.42 & 0.06 \\
\hline Car 4 & $(0.14,0.33,0.78)$ & 0.15 & 0.17 \\
\hline Car 5 & $(0.05,0.11,0.28)$ & 0.06 & \\
\hline
\end{tabular}

Table 12. Cars Evaluation for On Road Reliability- Expert 1

\begin{tabular}{|c|c|c|c|c|c|c|}
\hline Cars & Car 1 & Car 2 & Car 3 & Car 4 & Car 5 & Weightage \\
\hline Car 1 & $(1,1,1)$ & $(1,3,5)$ & $(7,9,9)$ & $(5,7,9)$ & $(3,5,7)$ & $(0.22,0.44,0.85)$ \\
\hline Car 2 & & $(1,1,1)$ & $(5,7,9)$ & $(3,5,7)$ & $(1,3,5)$ & $(0.13,0.28,0.63)$ \\
\hline Car 3 & & & $(1,1,1)$ & $(1 / 5,1 / 3,1)$ & $(1 / 7,1 / 5,1 / 3)$ & $(0.02,0.03,0.07)$ \\
\hline Car 4 & & & & $(1,1,1)$ & $(1 / 5,1 / 3,1)$ & $(0.03,0.08,0.21)$ \\
\hline Car 5 & & & & & $(1,1,1)$ & $(0.07,0.17,0.39)$ \\
\hline
\end{tabular}

Table 13. Average Weightage of cars for On Road Reliability

\begin{tabular}{|c|c|c|c|}
\hline Cars & Average Weightage & Defuzzification & Normalization \\
\hline Car 1 & $(0.40,0.87,1.83)$ & 1.04 & 0.42 \\
\hline Car 2 & $(0.25,0.58,1.34)$ & 0.72 & 0.29 \\
\hline Car 3 & $(0.07,0.14,0.33)$ & 0.18 & 0.07 \\
\hline Car 4 & $(0.10,0.22,0.52)$ & 0.28 & 0.11 \\
\hline Car 5 & $(0.07,0.19,0.49)$ & 0.25 & \\
\hline
\end{tabular}


Table 14. Cars Evaluation for After Sales- Expert 1

\begin{tabular}{|c|c|c|c|c|c|c|}
\hline Cars & Car 1 & Car 2 & Car 3 & Car 4 & Car 5 & Weightage \\
\hline Car 1 & $(1,1,1)$ & $(1,3,5)$ & $(7,9,9)$ & $(3,5,7)$ & $(5,7,9)$ & $(0.22,0.45,0.9)$ \\
\hline Car 2 & & $(1,1,1)$ & $(3,5,7)$ & $(1,3,5)$ & $(3,5,7)$ & $(0.11,0.26,0.61)$ \\
\hline Car 3 & & & $(1,1,1)$ & $(3,5,7)$ & $(1,3,5)$ & $(0.07,0.17,0.39)$ \\
\hline Car 4 & & & & $(1,1,1)$ & $(1,3,5)$ & $(0.03,0.09,0.22)$ \\
\hline Car 5 & & & & & $(1,1,1)$ & $(0.02,0.04,0.10)$ \\
\hline
\end{tabular}

Table 15. Average Weightage of cars for After Sales

\begin{tabular}{|c|c|c|c|}
\hline Cars & Average Weightage & Defuzzification & Normalization \\
\hline Car 1 & $(0.41,0.89,1.88)$ & 1.06 & 0.43 \\
\hline Car 2 & $(0.22,0.56,1.32)$ & 0.7 & 0.28 \\
\hline Car 3 & $(0.10,0.22,0.51)$ & 0.19 & 0.11 \\
\hline Car 4 & $(0.07,0.14,0.35)$ & 0.26 & 0.07 \\
\hline Car 5 & $0.07,0.19,0.52$ & 0.11 \\
\hline
\end{tabular}

Table 16. Result from Fuzzy AHP

\begin{tabular}{|c|c|c|c|c|c|c|}
\hline Criteria & $\begin{array}{c}\text { External } \\
\text { Appearance }\end{array}$ & Car Interiors & Add on Features & $\begin{array}{c}\text { On Road } \\
\text { Reliability }\end{array}$ & $\begin{array}{c}\text { After Sales } \\
\text { Service } \\
\end{array}$ & \multirow{3}{*}{ Weightage } \\
\hline Weightage & \multirow{2}{*}{0.36} & \multirow{2}{*}{0.23} & \multirow{2}{*}{0.16} & \multirow{2}{*}{0.09} & \multirow{2}{*}{0.16} & \\
\hline Cars & & & & & & \\
\hline Car 1 & 0.16 & 0.25 & 0.42 & 0.42 & 0.43 & 0.29 \\
\hline Car 2 & 0.15 & 0.31 & 0.29 & 0.29 & 0.28 & 0.24 \\
\hline Car 3 & 0.17 & 0.11 & 0.06 & 0.07 & 0.11 & 0.12 \\
\hline Car 4 & 0.08 & 0.14 & 0.17 & 0.11 & 0.07 & 0.11 \\
\hline Car 5 & 0.43 & 0.19 & 0.06 & 0.10 & 0.11 & 0.23 \\
\hline
\end{tabular}

\subsection{GRAModel}

On road car price, distance of service center from customer residence, mileage, power, torque and displacement are noted in numeric term, as shown in Table 17. All these values are normalized using smaller the better response for price, distance and larger the better for mileage, power, torque and displacement, as shown in Table 18. After normalization, deviation $(\delta)$ from smaller the better value is calculated to determine grey relation coefficient [2]. Table 19 shows deviation value and Table 20 shows grey relation coefficient and grey grade. On road price and mileage importance is considered as $40 \%$ and $30 \%$ respectively and remaining features contribute $30 \%$ towards quantitative criteria decision.

Table 17. Quantitative features of car in numeric terms

\begin{tabular}{|c|c|c|c|c|c|c|}
\hline Cars & $\begin{array}{l}\text { On Road Price } \\
\text { (Lakhs) }\end{array}$ & $\begin{array}{l}\text { Distance of } \\
\text { service } \\
\text { center }(\mathrm{kms})\end{array}$ & Mileage(kmpl) & Power(bhp) & Torque(Nm) & Displacement(cc) \\
\hline Car 1 & 5.05 & 2 & 20.5 & 67 & 90 & 998 \\
\hline Car 2 & 5.14 & 25 & 20.3 & 68 & 94 & 998 \\
\hline Car 3 & 4.82 & 45 & 20.63 & 67 & 104 & 1198 \\
\hline Car 4 & 4.82 & 45 & 23.01 & 67 & 91 & 999 \\
\hline Car 5 & 5.19 & 45 & 27.28 & 69 & 140 & 1047 \\
\hline
\end{tabular}

\begin{tabular}{|c|c|c|c|c|c|c|}
\hline Cars & $\begin{array}{l}\text { On Road Price } \\
\text { (Lakhs) }\end{array}$ & $\begin{array}{c}\text { Distance of } \\
\text { service } \\
\text { center }(\mathrm{kms})\end{array}$ & Mileage (kmpl) & Power(bhp) & Torque (Nm) & Displacement (cc) \\
\hline Car 1 & 0.38 & 1.00 & 0.00 & 0.03 & 0.00 & 0.00 \\
\hline Car 2 & 0.14 & 0.51 & 0.00 & 0.00 & 1.00 & 0.08 \\
\hline Car 3 & 1.00 & 0.00 & 1.00 & 0.04 & 0.00 & 0.28 \\
\hline Car 4 & 1.00 & 0.00 & 0.01 & 0.36 & 0.00 & 0.02 \\
\hline Car 5 & 0.00 & 0.00 & 0.25 & 1.00 & 0.00 & 1.00 \\
\hline
\end{tabular}

Table 19. Deviation $\delta$ Value

\begin{tabular}{|l|c|c|c|c|c|c|}
\hline Cars & $\begin{array}{c}\text { On Road Price } \\
(\text { Lakhs })\end{array}$ & $\begin{array}{c}\text { Distance of } \\
\text { service center } \\
(\mathrm{kms})\end{array}$ & 0.00 & $\begin{array}{c}\text { Mileage } \\
(\mathrm{kmpl})\end{array}$ & Power(bhp) & Torque (Nm) \\
\hline Car 1 & 0.62 & 0.49 & 1.00 & 0.97 & 1.00 \\
\hline Car 2 & 0.86 & 1.00 & 0.00 & 1.00 & 0.00 & 1.00 \\
\hline Car 3 & 0.00 & 1.00 & 1.00 & 0.96 & 0.92 & 0.00 \\
\hline Car 4 & 0.00 & 1.00 & 0.76 & 0.00 & 1.00 & 1.00 \\
\hline Car 5 & 1.00 & & 0.98 & 0.00 \\
\hline
\end{tabular}


Table 20. Table Grey relational coefficient and Grey relational grade

\begin{tabular}{|c|c|c|c|c|c|c|c|c|}
\hline Cars & $\begin{array}{c}\text { On Road } \\
\text { Price } \\
\text { (Lakhs) }\end{array}$ & $\begin{array}{c}\text { Distance of } \\
\text { service } \\
\text { center }(\mathrm{kms})\end{array}$ & Mileage(kmpl) & Power(bhp) & $\begin{array}{c}\text { Torque } \\
\text { (Nm) }\end{array}$ & $\begin{array}{c}\text { Displacement } \\
\text { (cc) }\end{array}$ & Grade & Normalization \\
\hline Car1 & 0.45 & 1.00 & 0.33 & 0.34 & 0.33 & 0.33 & 0.43 & 0.16 \\
\hline Car3 & 1.00 & 0.33 & 1.00 & 0.34 & 0.33 & 0.41 & 0.66 & 0.24 \\
\hline Car4 & 1.00 & 0.33 & 0.33 & 0.44 & 0.33 & 0.34 & 0.63 & 0.23 \\
\hline Car5 & 0.33 & 0.33 & 0.40 & 1.00 & 0.33 & 1.00 & 0.59 & 0.22 \\
\hline
\end{tabular}

\subsection{Combination of Qualitative and Quantitative Score}

Previous sections calculate car score based on Qualitative and Quantitative criteria, using expression:

$$
\text { Car Score }=\alpha 1 * \text { Qualitative Score }+\alpha 2 * \text { Quantitative Score }
$$

These sections combine scores considering weights for qualitative and quantitative model, shown in Table 21.

Table 21. Final Car Score and Rank

\begin{tabular}{|c|c|c|c|c|}
\hline \multirow{2}{*}{ Cars } & \multicolumn{2}{|c|}{ Normalized Weightage } & \multirow{2}{*}{ Final Score } \\
\cline { 2 - 4 } & Qualitative $\alpha 1-0.35$ & Quantitative $\alpha 1-0.65$ & 0.16 & 0.2055 \\
\hline Car 1 & 0.29 & 0.15 & 0.1815 & 0.1980 \\
\hline Car 2 & 0.24 & 0.24 & 0.1880 & 5 \\
\hline Car 3 & 0.12 & 0.23 & 3 & 0.2235 \\
\hline Car 4 & 0.11 & 0.22 & 4 \\
\hline
\end{tabular}

\section{Conclusion}

The selection of cars from various available models, considering all quantitative and qualitative features, is a complex multicriteria decision making problem. Car selection problem is difficult to handle and its complexity increases with unclear and vague opinions of family members. The proposed analytical solution approach using Fuzzy AHP and GRA has been demonstrated in this paper to assess the five different car models available in market within price budget of 5.5 Lakh. The individual levels of importance for each qualitative criterion are stated through weights and each car features are then evaluated using Fuzzy AHP approach. So, it can eliminate the bias due to subjective judgment. GRA is used for quantitative criteria to state individual car score. Later normalized score of qualitative and quantitative criteria for individual car is integrated to get final car score.

The result of hybrid approach gives a ranking of cars that helps car selection. Car 5 is found to be the rank one car. Car 5 is Indian brand car that launched in year 2016. The price of car is 5.19 Lakhs and having good power, mileage, torque and displacement but have only two service station around $45 \mathrm{kms}$ from X's residence. Car 1 is an Indian brand car with good service but box design and placed two even though its qualitative features are much better than that of Car 5. Car 3, Car 4 and Car 2 are placed third, fourth and fifth rank respectively. The approach decides car ranking by considering all the necessary features required to be taken into account during car buying process. Vagueness and subjectivity in decision making is taken care by hybrid approach.

Further change in weights of qualitative and quantitative preferences will change car ranking which will help decision maker to decide car selection based on his preferences. The approach can further be extended to other multi criteria problems with qualitative and quantitative features. The results of approach can also be compared with other integrated approaches. Finally, we can conclude that hybrid AHP and GRA can be considered as one of multi criteria decision making approach.

\section{References}

1. M. Aruldoss, T. M. Lakshmi, and V. P. Venkatesan, "A survey on multi criteria decision making methods and its applications," American Journal of Information Systems, vol.1 no.1, pp. 31-43, 2013.

2. F.T. Chan, and N. Kumar, "Global supplier development considering risk factors using Fuzzy extended AHP-based approach," Omega, vol.35, no. 4, pp. 417-431, 2007.

3. I. Ertugrul, T. Oztas, A.Ozcil, GZ. Oztas, "Grey Relational Analysis Approach In Academic Performance Comparison Of University: A Case Study Of Turkish Universities," European Scientific Journal, 1 June 2016 (Special Edition). 
4. R.C.P. Eusebio, A.P.Huelgas-Orbecido, M.A.B. Promentilla, "Optimal selection of desalination systems using fuzzy AHP grey relation analysis,” Chemical Engineering Transactions, vol. 52, pp. 649-654, 2016 (DOI:10.3303/CET1652109)

5. S. Li, H. Yan, "Study on applying fuzzy AHP and GRA in selection of agent constructive enterprise," International Journal of Social, Behavioural, Educational, Economics, Business and Industrial Engineering, vol. 5, no. 6, pp. 899905, 2011.

6. D. K. Mahalik, "Selection of a plant site: A multi Criteria Decision Making Using AHP and GRA," Journal of Supply Chain Management System, vol. 1, no. 4, pp 23-29, 2012.

7. S. Mahmoodzadeh, J. Shahrabi, M. Pariazar, and M. S. Zaeri, "Project selection by using fuzzy AHP and TOPSIS technique," International Journal of Human and social sciences, vol.1, no.3, pp. 135-140, 2007.

8. A. N. Patil, V. N. Gaitonde, and M. H. Dani, "Supplier selection using fuzzy integrated approach, "International Journal of Management Research and Reviews, vol.4, no. 6, pp.660, 2014.

9. M. Prabhakaran, A.N. Patil, Nagaraj Raikar, Sidharth. K, "Experimental Investigation on as Laser Cutting,"4th International Conference on Recent Trends in Engineering Science and Management, ISBN 978-93-86171-01-6, pp. $127-138,7^{\text {th }}$ August 2016

10. D. Rossi, E. Bertoloni, M. Feraroli and F. Marciano, "A multi-criteria ergonomic and performance methodology for evaluating alternatives in manuable material handling," International Journal of Industrial Ergonomics, vol.43, no. 4, pp. 314-327, 2013.

11. T. Sari, K. Baynal and O. Ergul, "Supplier Selection with Grey Relational Analysis," International Journal of Emerging Research in Management \& Technology, vol.5, pp. 61-70, 2016.

12. D. Stanujkic, B. Dordevic, and M. Dordevic, "Comparative analysis of some prominent MCDM methods: A case of ranking Serbian banks," Serbian Journal of Management, vol. 8,no.2, pp. 323-241, 2013.

13. E. Triantaphyllou, and S. H. Mann, "Using the analytic hierarchy process for decision making in engineering applications: some challenges,"International Journal of Industrial Engineering: Applications and Practice, vol. 2, no.1, pp.35-44, 1995.

14. P. J. M. Van Laarhoven and W. Pedrycz, "A fuzzy extension of Saaty’s priority theory," Fuzzy Sets and Systems, vol. 11, no. 3, pp. 229-241, 1983.

15. Y. M. Wang and K. S. Chin, "Fuzzy analytic hierarchy process: A logarithmic fuzzy preference programming methodology," International Journal of Approximate Reasoning, vol. 52, no.4, pp. 541-553, 2011.

Amol NayakappaPatil is Assistant Professor in Department of Mechanical Engineering at Agnel Insitute of Technology and Design, Assagao, Bardez, Goa, India. He did his Master in Production Management in 2014 from BVBCET - Hubli, Karnataka. His areas of interest are Six Sigma, Quality Management, Lean Management and Supply Chain Management.

Niraj G.Pai Bhale is a Research Scholar in Periyar Maniammai University, Tamilnadu, India and Assistant Professor and Head of Mechanical Engineering at Agnel Institute of Technology and Design, Assagao, Bardez, Goa, India. He did his Master in Industrial Engineering from Goa University in 2007. His research interest is in the field of Six Sigma Management, Supply chain management and Operations and Project management.

NagrajRaikar is an Assistant Professor in Department of Mechanical Engineering at Agnel Insitute of Technology and Design, Assagao, Bardez, Goa, India. He did his Master in Production Management in 2012 from BVBCET - Hubli, Karnataka. His area of interest are Supply Chain Management, CAD-CAM, Industrial Engineering, Work Study, Lean Management.

M. Prabhakaran is Assistant Professor in Department of Mechanical Engineering at Agnel Insitute of Technology and Design, Assagao, Bardez, Goa, India. He did his Master in Manufacturing Engineering in 2013 from M.A.M. College of Engineering, Trichy, Tamilnadu. His areas of interest are Six Sigma, Manufacturing, Unconventional Machining Processes, Optimization and Modeling. 